\title{
The right brew? An analysis of the tourism experiences in rural Taiwan's coffee estates
}

\begin{abstract}
The main goal of this research was to analyze the tourism experiences offered by coffee estates in Taiwan. A mixed-methods approach was applied in two main parts. First, the profiles of Taiwan coffee estates were examined in terms of the experiences provided to engage visitors. In-depth interviews with owners indicated they can be categorized into traditional, educational, and comprehensive coffee estates. Second, using the memorable tourism experiences scale (MTES), the resulting visitor survey findings were overwhelmingly positive. However, four specific recommendations were made for the sustainable development of coffee estate tourism in Taiwan: increasing and improving marketing and branding by government-run destination management organizations; developing an integrated tourism supply system and value chain in areas containing coffee estates; creating new coffee tour products with travel agencies and tour operators; and establishing education as the key selling point of coffee estates. These four initiatives will contribute to solving some of the challenges Taiwanese coffee estates are currently facing, while continuously developing the niche market of coffee estate tourism.
\end{abstract}

Keywords: Coffee tourism; coffee estates; experience design; memorable tourism experiences scale (MTES); rural tourism; destination marketing and branding; Taiwan

\section{Introduction}

The optimistic view of rural tourism is that it improves the social and economic growth of rural areas (e.g., Gursoy, Chi, \& Dyer 2010; Irshad, 2010; Rekom \& Go, 2006; Trukhachev, 2015). Some researchers have recognized the potential of coffee tourism as a development tool for local communities and argued that coffee tourism may help sustain the economic and social bases of rural areas (Jolliffe \& Kwan, 2010; Karlsson \& Karlsson, 2009; Lyon, 2013; Rogerson \& Rogerson, 2014). Several Asian countries, such as Malaysia, Vietnam, Thailand, and Indonesia, have rich coffee histories and cultures, offering tourism activities such as selecting coffee beans, roasting, and tasting. However, the characteristics of coffee producers in many regions (Gathura, 2013; Sick, 2008; Utting-Chamorro, 2005) present challenges in using coffee tourism for economic benefit (Jolliffe, 2010; Karlsson \& Karlsson, 2009). Moreover, coffee tourism is less widely accepted by academia and the public than wine tourism (Yun, 2014), even if coffee is consumed and experienced on many trips.

In Taiwan, the coffee industry became a policy focus after the devastating earthquake in 1999. A large area of betel nut planting was changed into coffee production in Yunlin and 
Nantou counties. Through several trials, the techniques of coffee production were improved. Many farmers learned the management of coffee planting and witnessed the growing consumption of coffee in the domestic market and worldwide. Most coffee estates are managed by younger generations of families, who went to cities for their educations and then returned home to devote themselves to the coffee business. These younger-generation entrepreneurs often participate in coffee-related competitions for marketing purposes or design different experiences to engage visitors. Taiwanese people's demand for coffee shifted from the stimulant beverage of earlier years to evaluations of coffee and health considerations, as people started paying more attention to the origins, environments, and roasting and processing of coffee. The third wave of the coffee revolution is as we see today. Being more of a new niche market, coffee experiences are not deeply explored in the tourism literature.

Recently, more researchers have begun to explore the factors characterizing memorable tourism experiences (MTEs) and the destination attributes affecting MTEs (Chandralal \& Valenzuela, 2015; Kim, Ritchie, \& McCormick, 2012; Kim \& Ritchie, 2014; Tung \& Ritchie, 2011). Tung and Ritchie (2011) emphasized that in addition to encouraging revisits and spreading positive word-of mouth, the elements of what makes certain experiences special, spectacular, or truly memorable are worth studying so that tourism planners can develop environments within which tourists can create their own MTEs. Chandralal and Valenzuela (2013) also suggested that destination management organizations (DMOs) should change marketing strategies from being highly focused on destination attributes to emphasizing experiential aspects. As a new niche market, coffee tourism is worth exploring in the scholarly literature (Yun, 2014).

A review of the previous literature showed that there are gaps in the research on coffee tourism. Few studies have examined the typologies of coffee estates and the MTEs of the visitors after participation in the experiential activities provided by different types of coffee estates. Moreover, this type of analysis has heretofore never been attempted in Taiwan. Comparing the status of coffee tourism experiences from both the supply and demand sides was at the core of the research problem.

The main goal of this research was to analyze the tourism experiences offered by coffee estates in Taiwan. It applied a mixed-methods approach beginning with an examination of the profiles of Taiwan coffee estates in terms of the experiences provided to engage visitors. In-depth interviews with owners indicated they are categorized into traditional, educational, and comprehensive coffee estates. Then the memorable tourism experiences scale (MTES) was used to analyze experiences remembered and recalled by visitors after having visited Taiwan coffee estates. 


\section{Literature Review}

\subsection{Rural and coffee tourism}

Rural tourism provides opportunities for visitors to have contact with nature, scenic landscapes, and culture in the countryside and may support the sustainability of local communities. In addition, the social, emotional, hedonic and symbolic dimensions of rural tourism have attracted recent studies in the context of tourism experiences (Kastenholz et al., 2012; Williams \& Soutar, 2009). Tourism developments generally increase investment, employment, and commercial activities, which allow residents to engage in, obtain income from, and increase living standards (Ghapar, Jamal, \& Ahmad, 2015). Additionally, residents can be motivated by tourism developments to preserve existing natural areas and habitats, so that these lands receive more effective stewardship (Scherl \& Edwards 2007; Nursey-Bray \& Rist, 2009). Academics also argue that when tourists enter rural areas and interact with residents, they better appreciate local cultures and become more aware of the importance of their own cultural heritage and engage in its protection (Mason, 2008).

Coffee, as a popularly consumed beverage, is geographically connected with its area of production (Jolliffe \& Kwan, 2010). Although coffee is consumed and experienced on many trips, coffee tourism in rural areas is less widely accepted by academia and the public than wine tourism (Yun, 2014), and the study of coffee tourism typologies are scant. Karlsson and Karlsson (2017) categorized wineries into traditional, educational, and comprehensive types. Traditional wineries are primarily committed to grape and wine production. When tourists visit these vineyards, they engage in winery tours, tasting and purchasing wine; no special events or educational activities are arranged. Educational wineries not only provide tours and wine samples, but also offer classes and hands-on experiences that create greater wine-related knowledge. Comprehensive wineries schedule activities in addition to tours, wine-related workshops, and hands-on experiences, such as food, lodging, and local sightseeing.

With regards to coffee, some researchers link its cultural aspects in production and consumption with tourism (Stylianou-Lambert, 2011), agritourism (Liu et al., 2017; Rogerson \& Rogerson, 2014), and culinary tourism (Kleidas \& Jolliffe, 2010). Yun (2014, p. 35) explored the opportunities, challenges, and initiatives for coffee tourism in Ethiopia and defined coffee tourism as follows:

Coffee tourism can be defined as a form of commodity tourism that provides opportunities for tourists to engage in coffee experiences of all aspects in places that contain unique nature and/or culture associated with coffee. It is not simply a combination of coffee and tourism. Coffee tourism works as a development vehicle for people or countries involved in the coffee industry. It can be conducted in both rural and 
urban areas while providing benefits to coffee growers and coffee workers.

Several researchers have recognized the potential of coffee tourism as a development tool for local communities (Jolliffe \& Kwan, 2010; Karlsson \& Karlsson, 2009; Lyon, 2013; Rogerson \& Rogerson, 2014). For example, Karlsson and Karlsson (2009) examined coffee tourism from a regional perspective and argued that it may help sustain the economic and social bases in rural areas. Anbalagan and Lovelock (2014) suggested that coffee offers a niche market through developing various tourism activities associated with this product. Kastenholz et al. (2012) argued that understanding how tourism experiences are supplied and managed in rural destinations is essential to achieving sustainable rural tourism development and the co-creation of tourism experiences in terms of social, emotional, and symbolic dimensions is important for enhancing visitor satisfaction.

Kleidas and Jolliffe (2010), based on Swarbrooke (1995), described the range and diversity of coffee-related tourism in the following typology:

- Natural attractions (e.g., coffee-growing areas and landscapes).

- Human-made but not originally designed to attract tourists (e.g., historical coffee houses and traditional cafes).

- Human-made and purpose built to attract tourists (e.g., coffee museums).

- Festivals and special events (e.g., coffee festivals).

Jolliffe (2010) identified three basic types of coffee destinations. Coffee-producing destinations are coffee plantations that are open to visitors such as those found in Colombia. Coffee-culture destinations are places where significant café cultures have emerged such as in Seattle, Washington, and Vienna. Coffee-history destinations are associated with the history of coffee production, sale and consumption as evidenced by the exhibits in the Bramah Tea and Coffee Museum in London, and the Coffee Museum in Dubai.

More Taiwanese like are choosing to have leisure activities in rural areas and coffee tourism has attracted more researchers' and destination marketers' attention in recent years (Huang, 2017). In the past two decades, the Taiwan government and coffee farmers have devoted much effort to the coffee industry. However, more in-depth investigation of the typology of coffee estates is needed to understand the connection of coffee and tourism and the way these Taiwanese estates create coffee destination experiences.

\subsection{Tourism experiences}

Coffee producers in many regions (Gathura, 2013; Sick, 2008; Utting-Chamorro, 2005) face challenges in using coffee tourism for economic benefit (Jolliffe, 2010; Karlsson \& 
Karlsson, 2009). Huang (2017) found that the destination brand as well as cooperative marketing networks are important in coffee destination development. Chandralal and Valenzuela (2013) suggested that DMOs should convert marketing strategies from being highly focused on destination attributes to ones emphasizing experiences. However, before the DMOs modify marketing strategies to experience-based, the experiences need to be more clearly understood? For example, what are the main attributes of tourism experiences and should they be measured?

The investigation of tourism or tourist experiences is not new. Cohen (1979) applied sociological theories to argue that tourist experience is not something essentially spurious nor superficial as previous studies had indicted. He proposed a continuum of types of tourist experience (existential, experimental, experiential, diversionary, and recreational) that are associated with an individual's travel motivations, highlighting the dynamic and complicated nature of a tourism experiences. Mannell and Iso-Ahola (1987) discussed the "unique" and "individual" nature of an experience from a more psychological perspective and identified the imaginative, emotional, symbolic, aesthetic, and appreciative attributes of leisure and tourism experiences. Since tourism experiences are complex and dynamic, measurement of such is a challenge for researchers. Therefore, recent studies have focused on identifying the main dimensions related to a particular experience with Pine and Gilmore (2011) pointing out that understanding the fundamental features of an experience is the basis for improving the success of leisure and tourism businesses.

Arguing that the main product of the tourism sector is "service", Otto and Ritchie (1996) developed a scale of service experience in tourism and tested it across three different tourism subsectors: hotels, airlines, and tours and attractions. They found that "hedonics" was the main dimension of service experiences and followed by peace of mind, involvement, and recognition. More researchers started exploring the factors characterizing memorable tourism experiences (MTEs) and the destination attributes affecting MTEs (Chandralal \& Valenzuela, 2015; Kim, Ritchie, \& McCormick, 2012; Kim \& Ritchie, 2014; Tung \& Ritchie, 2011). For example, Tung and Ritchie (2011) emphasized that in addition to encouraging revisits and spreading positive word-of mouth, the elements of what makes certain experiences special, spectacular, or truly memorable are worth studying so that tourism planners can develop environments within which people can create their own MTEs. They identified affect, expectations, consequential reality, and recollection as the four key constructs of memorable experiences.

Extending Tung and Ritchie's (2011) work, Kim, Ritchie, and McCormick (2012) defined memorable tourism as "a tourism experience positively remembered and recalled after the event has occurred." They identified seven distinct dimensions with 24 items that characterize MTEs. The first dimension is hedonism, which asks the participants whether they felt thrilled about the new experience, indulged in the activities, enjoyed the experience 
or found it exciting. The second is novelty, which is about whether the experience was unique, different from what they have tried before, or furthermore, whether it was a once-in-a-lifetime experience. The third dimension, local culture, is about social interaction with residents and the impressions about the local culture and people. The fourth component, refreshment, is related to the emotions of visitors during trips, if they found the stay liberating, enjoyed a sense of freedom, or felt refreshed and revitalized. The fifth dimension, meaningfulness, allows visitors to evaluate if they think the experience was meaningful, that they did something important or learned more about themselves. The sixth dimension is involvement. Then visitors are asked about their intentions, whether they visited a place they really wanted to visit and/or did things they really wanted to do, and whether they were interested in the main activities. The last component is knowledge, checking if the visitors were able to explore, gain knowledge, and find out something new about local culture.

Besides Kim's work, several scales are available to measure MTEs. For example, the MTE instrument developed by Chandralal and Valenzuela (2015) included ten experiential dimensions: authentic local, novel, self-beneficial, significant travel, serendipitous and surprising, local hospitality, social interactions, impressive local guides and tour operators, fulfillment of personal travel interests, and affective emotions. They further pointed out that the relative importance of these dimensions differs according to the destinations' and travelers' demographic characteristics. Based on his first exploration, Kim's (2018) extended his MTES and developed another scale related to measure destination attributes associated with MTEs. He identified ten dimensional constructs (i.e., local culture, variety of activities, hospitality, infrastructure, environment management, accessibility, quality of service, physiography, place attachment, and superstructure) affecting MTEs.

As Kim and Ritchie (2014) pointed out that due to the phenomenal growth of destination competition, effectively delivering significant MTEs is critical for remaining competitive. Therefore, the current study investigates the MTEs of coffee estate visitors. More specifically, what is the major dimension of MTEs that influences them the most? Are there differences between different types of coffee estate visitors? Based on the literature review, the MTES developed by Kim, Ritchie and McCormick (2012) is so far the most applicable and has been proven valid in several previous studies.

\section{Methods}

This study adopted a mixed-methods approach with an exploratory sequential design (Creswell \& Clark, 2011), which is a qualitative exploration phase followed by a quantitative survey. The strength of mixing both methods is that the qualitative and quantitative data complement each other and provide a more holistic picture of the tourism experiences and management strategies of coffee estates in Taiwan. 


\subsection{Semi-structured interviews}

The first phase employed semi-structured in-depth interviews with coffee estate owners to develop a coffee estate typology. The purposive sampling technique was used to select interviewees. Six coffee estate owners were finally chosen because they have participated in a famous coffee competition in Taiwan and were recommended by coffee experts. The estates also fit the following three criteria: 1) open to the public, 2) provide coffee experience activities, and 3 ) offer coffee tours.

Two professional trained interviewers visited the coffee estates from October to December 2017. The interview questions included four major categories: 1) marketing, branding, and management strategies, 2) touristic or experiential activities, 3) generational differences regarding methods of operation, and 4) influences of the estate and the coffee tourists on the local community. All interview data were recorded and transcribed verbatim into NVivo software for further analysis.

Several techniques were used to ensure the accuracy of the analysis. First, the research team performed a preliminary exploration by processing each transcript independently. Second, independent researchers identified the themes that emerged from the data and labeled the pervasive ideas related to characteristics, experiential activities, marketing, branding, management, and operational strategies of the coffee estates. Then, the team conducted an inter-coder agreement checks through a series of discussions to verify the codes. Finally, the researchers conducted thematic analysis, which compared and interrelated themes across different coffee estates. Through constantly triangulating different sources of information and literature, the analyses were completed until the team could not find any new information emerging from the data (Creswell, 2012).

\subsection{Quantitative survey}

In phase two, the study adopted Kim, Ritchie, and McCormick's (2012) memorable tourism experience scale (MTES) to investigate the tourism experiences with a large sample of visitors. MTES has been validated by several empirical studies and has been proven as a reliable measurement scale (e.g., Kim \& Ritchie, 2014; Kim, 2018). Through the quantitative survey based on MTES, the researchers were able to identify the most salient dimensions of tourism experiences perceived by the coffee estate visitors. Furthermore, the quantitative data collected from visitors complemented the first phase interviews, which placed the emphasis on owners' perspectives. The researchers also compared variations in visitors' tourism experiences delivered by different types of coffee estates. 


\subsubsection{Instrumentation}

Because the original scale is written in English, which is not the predominant language in Taiwan, a two-step translation technique was employed to preserve the reliability of each survey item across linguistic boundaries. In the first step, one of the authors, a native Mandarin Chinese speaker, translated the original English items into Traditional Chinese. Two Chinese native speakers with high levels of English proficiency were then hired to confirm the meanings of each item. A face-to-face meeting was held with the two independent researchers to verify the equivalency between the two linguistic versions. After a thorough discussion, all the researchers came to an agreement on the final Traditional Chinese version of the questionnaire.

All the measurement items were on a five-point Likert-type scale from 1 (strongly disagree) to 5 (strongly agree). The first section of the questionnaire collected the participants' background information. The second section was composed of the seven MTES dimensions: hedonism, novelty, social interaction and local culture, refreshment, meaningfulness, involvement, and knowledge. The 24, five Likert-scale items in the seven-dimension model are shown in Figure 1. The questionnaire is included as Appendix A.

[Insert Figure 1 about here]

\subsubsection{Data collection and analysis}

The questionnaire survey was administered at the chosen coffee estates. This enabled the researchers to record and compare the differences of tourism experiences of different types of coffee estates. The survey was self-completed using a purposive sampling technique. Hard-copy questionnaires were sent to the coffee estate owners to distribute to visitors. Besides, digital questionnaires were sent to visitors through online instant messaging (LINE) groups. As a result, the sample consisted of 295 Taiwanese visitors. Based on the approach proposed by MacCallum, Browne, and Sugawara (1996), the sample size is large enough to reject a Type II error (the estimations based on the criteria of alpha $=0.05$, desired power $=$ 0.80 , RMSEA for $\mathrm{H} 0=0.05$, RMSEA for $\mathrm{Ha}=0.01$ ).

The analyses followed an inductive strategy. Before conducting the descriptive or factor analysis, all datasets were screened using SPSS 21.0 to test for univariate normality and missing values. First, all variables were assessed for skewness and kurtosis. The results indicated that no variable had extreme non-normality (Curran, West, \& Finch, 1996). The data were examined using Little's missing completely at random (MCAR) test in SPSS with a significant result $(p<0.01)$. Therefore, all missing values were assumed missing at random (MAR). The expectation-maximization (EM) algorithm, which has a relatively unbiased 
parameter estimation, was used to impute the incomplete data (Enders, 2001; Graham, 2009).

Since MTES has been validated by previous studies, confirmatory factor analysis (CFA) instead of exploratory factor analysis (EFA) was performed to test the hypothesized memorable-tourism-experience model (Figure 1). Furthermore, to compare the latent mean differences of first-order latent factors (hedonism, novelty, social interaction and local culture, refreshment, meaningfulness, involvement, and knowledge.) and second-order latent factor (memorable tourism experience) between two different visitor groups, the means and covariance structures (MACS) approach within the framework of CFA modeling was conducted using EQS 6.3 software.

According to Byrne and Stewart (2006), at least two conditions should be achieved to test the latent mean differences. First, for the second-order model, equality constraints should be placed on all factor loadings and intercepts of the observed variables. Specifically, the forward (sequential constraint imposition) approach was used in which a series of hierarchically nested CFA models were tested (Byrne, 2013). This process examined the invariance of factor loadings and intercepts across two samples. When the difference of the comparative fit index (CFI) is smaller than 0.01 (Cheung \& Rensvold, 2002), invariance across groups is accepted. Secondly, the latent factor means for one group must be fixed to zero, which operates as the reference group (the visitor group of non-educational coffee estates was the reference in this study). As a result, factor intercepts can be interpreted in a relative sense. The statistical significance was determined by the $\mathrm{z}$ statistic (Byrne \& Stewart, 2006).

\section{Results}

\subsection{Coffee estate typology}

Currently, there are no travel agencies offering coffee tours in Taiwan. Those who visit the coffee estates are coffee enthusiasts, participating in organizational field trips, or merely passing by. Based on the analyses of the qualitative data, the core activities provided by most Taiwanese coffee estates are coffee experiential activities and estate tours (Table 1). Few estates provide training courses and lodging services. Furthermore, experiential learning activities mainly focus on the plantations, and the roasting and tasting of coffee, which last for a half to two days (Figure 2). Consequently, visitors become more familiar with the estate's own branded coffees. In addition, these activities vastly increase the probability that visitors may buy the coffee product.

Based on the main activities and operation methods, the six visited Taiwanese coffee estates were categorized into three types: traditional, educational, and comprehensive. The traditional coffee estates concentrate mainly on their coffee plantations. As shown in Table 1, they may provide estate tours or coffee tasting for visitors, but no design of specific 
experiential activities is involved. Some are in remote areas and people must make appointments in advance of their visits. Tourism is not the main source of income for these estates. A similar phenomenon was noted in Anbalagan and Lovelock's (2014) study for Rwanda. The owners indicated that seasonality and the logistics of coffee tourism are challenging especially when visitors came during harvesting seasons.

[Insert Table 1 about here]

Educational coffee estates not only grow coffee beans but provide visitors with tours and coffee samples. They also provide classes and hands-on experiences to educate their guests about coffee-related knowledge. For example, one educational coffee estate has received several awards from coffee bean competitions, creating a notoriety that attracts many coffee lovers. This estate offers courses on coffee farm management and coffee roasting with more in-depth instruction. If participating in the classes, visitors can gain first-hand experiences working with the experts.

Comprehensive coffee estates have coffee plantations, coffee-related activities, and offer meals and accommodations. For example, one of the comprehensive coffee estates is located at Sun-Moon Lake, a very popular tourist destination in Taiwan. After participating in experiential activities in the coffee estate (not as sophisticated as the educational estates) many visitors also extend their trips to nearby tourist attractions.

Based on the interviews, it was concluded that coffee tourism in Taiwan is still in a relatively embryonic stage, compared to the tours in Southeast Asia, which generally are extended into cafes in downtown areas (Table 2). This is possibly because of travel agent and tour operator involvement, and a higher proportion of international visitors. The greater variety of activities accommodates much more diverse interests, and possibly enhances visitors' memorable tourism experiences. Presumably, the productivity, revenues and profitability of coffee estates are also increased. However, this needs further analysis and verification.

[Insert Table 2 about here]

\subsection{Coffee estate marketing and branding}

The management and operation methods of the Taiwan coffee estates were analyzed through observations and in-depth interviews with owners. Special attention was paid to exploring the marketing and branding of coffee tourism experiences. Furthermore, the marketing by the coffee estates was reviewed in terms of their products, pricing, distribution channels, and promotions. Based on the themes emerged from interviews, it was found that the owners focused mainly on plantation and sales of coffee products rather touristic 
activities. The three dominant themes are described below.

\subsubsection{Culture has influences on brand building strategy (Theme 1)}

Most of the coffee estates in Taiwan are connecting themselves with local cultures and blending them their brand to create uniqueness. The names of the coffee estates usually reflect the connections of the estates and local tribes, cultures, and geography. For example, an estate in an aboriginal area, is adapting indigenous tattoos, images, arts and crafts to simulate an aboriginal atmosphere. An estate in a community full of legends, integrates relevant elements into the coffee experiences:

- I used the name of my tribe to be the first word of the coffee estate to show my origin (Estate $\mathrm{C}$ owner).

- Our estate is near the source of water and full of legends, so we used the word "legend" to name our estate (Estate E owner).

- We are the coffee estate of the highest altitude. So, I decided to combine "lofty" and "peak" as the name of the estate (Estate B owner).

\subsubsection{Coffee tours ae nit just a "coincidence" and a way to relax (Theme 2)}

Most owners believe that travel agencies might get large commissions from selling coffee tours and they will not benefit much from such business deals. Therefore, they did not make conscious efforts to brand their businesses for tourism since their principal focus is on plantations and sales of coffee beans. For example, the owners of Estate A and B said the following:

- We started to grow coffee beans because my family likes coffee. Gradually, we thought it is a good idea that we can provide a place and some experiences and share our coffee to coffee lovers. We are not clear about what specialties we should create (Estate D owner).

- I started the coffee tours because I won coffee competitions. More and more people would like to visit my coffee estate. So, I thought it was a good idea to provide a space for visitors to learn coffee knowledge. I didn't think about what elements I should include in the coffee tour (Estate $\mathrm{C}$ owner).

The coffee tourism experiences in Taiwan are, therefore, extensions from coffee estates, which were established to plant and sell coffee beans. No strategic marketing and branding strategies for tourism are evident. Most of the coffee estates are in rural areas and people visit them during holidays. They generally provide relaxing environments: 
- I hope that every visitor can enjoy a cup of coffee in a relaxing way (Estate A owner).

- I expect that visitors can realize that we have good coffee in Taiwan and have a better understanding of coffee (Estate F owner).

- I hope to provide food for thought for visitors to understand how coffee is grown and brewed and consequently they can experience the goodness of coffee afterwards (Estate $\mathrm{C}$ owner).

In addition, through teaching and sharing, the owners hope that visitors not only get to know coffee better but also purchase their estates' coffee beans. The following quotes from owners demonstrate these points:

- I hope to provide a place to all the customers to forget the hustle and bustle of urban life and relax themselves in my estate (Estate $\mathrm{C}$ owner).

- Through all the experiencing activities to educate the customers to cherish each cup of coffee (Estate B owner).

- The visitors used to feel that the beans produced in Taiwan are too expensive for them to buy. However, after the estate visit, they changed their mind and are willing to pay more for the coffee beans. (Estate E)

- I often tell the visitors to define the value of the coffee beans after the trip around the estate. They are usually more than happy to buy the coffee beans. (Estate F)

\subsubsection{Word-of-mouth is the most powerful marketing tool (Theme 3)}

The localization of coffee estates results in differentiated products while the businesses operate with a relaxing and educational approach. Most of the coffee estate offerings are not connected with other tourism products. This implies that the coffee tours are single-destination products, which visitors arrange by themselves or they are booked by other (non-tourism) organizations. The coffee tourism experiences are similar, which includes picking coffee beans, roasting beans, and brewing coffee. Since the estates' core product is coffee beans, they hope that visitors will buy the beans after their experiences. Coffee tasting is arranged as the final activity to pique visitors' intention to purchase. Also, the price is lower than the coffee visitors can buy in markets at home. The owners rely mostly on word-of-mouth promotion expecting that visitors will make recommendations to friends and relatives, as reflected in these two owners' quotes:

- My estate became famous after I won several competitions. So, through competitions, people got to know me, and they want to visit my estate (Estate owner C).

- I don't like to spend money on commercials or social media because if customers like 
our estate, they will post their experiences online, which is sincere and effective (Estate owner D).

Interestingly, different marketing approaches were found for first- and second-generation coffee growers. The first generation believes that spending time to establish relationships with customers and lowering the prices of coffee beans are the best ways of marketing. However, younger- generation owners prefer to earn customers' recognition of their products and utilize online selling.

- In the past, my father usually chatted with the visitors to build up relationships and then he started to sell our products. My approach is different that I immediately tell the visitors about the strength and uniqueness of our products when they arrive so that they can make decisions quickly. (Estate C)

- I emphasize on how to persuade the customers to buy our products, but my father will reduce the price to sell the products. Thus, my father and I need to communicate with each other about the pricing strategies. (Estate D)

In general, the coffee estates in Taiwan are still operating as if in a primary industrial sector, with the focus on plantation operations. They assume that customers will buy their coffee if they have positive perceptions of its qualities. Jolliffe, Kwan, and Yen's (2010) study on international tourist experiences with coffee in Vietnam, found that over half of their subjects would buy coffee-related souvenirs but few dedicated coffee tours existed. They recommended that tour companies develop coffee experience packages within the context of the culinary heritage of Vietnam. However, to increase tourist motivations to join coffee tours in Asia, both push (internal reasons) and pull factors (destination attributes) should be considered when designing such activities (Devesa, Laguna, \& Palacios, 2010).

Another owner dilemma is that they cannot handle large numbers of visitors due to a lack of manpower, which was also the situation highlighted in Anbalagan and Lovelock's (2014) study. With such passive marketing approaches being adopted, only coffee enthusiasts or those who participate in the tours arranged for them by their organizations may visit coffee estates.

- Our estate also wants to receive more visitors; however, only my father and I run this business now. We have some part-time workers but not enough manpower to handle too many visitors. (Estate D)

- Tourists are not stable, so it is not cost-effective to hire one employee. If there are more visitors, we ask our neighbors to help us. Sometimes, they are busy as well, so we have the problem of manpower shortage. (Estate C) 
Niche market tourism focusing on culture, food and wine are usually designed to offer in-depth experiences and involve learning (Jolliffe, 2010). This challenges the coffee estates to provide well-trained, hospitable tour guides and skilled coffee course instructors. The coffee estates in Taiwan implicitly apply "sensory marketing", which involves visitors' smell, taste and touch in the activities provided (Krishna, 2011). Almost every visited estate has coffee tasting to impress visitors with the aroma of ground coffee beans and freshly brewed coffee. However, more active marketing strategies are needed to effectively promote coffee tours and the sustainable development of the local communities.

\subsection{Results from visitor survey}

\subsubsection{Respondents' profile}

A total of 420 questionnaires were distributed (between May 10 and August 10, 2018) and 295 valid completed forms were collected, for a response rate of $70.2 \%$. As shown in Table 3, the sample is slightly skewed toward female $56.3 \%$. Most respondents were between 46-64 years old (47.5\%), followed by 30-45 (31.2\%), and 19-29 (15.6\%). Some 62.7\% spent less than NT $\$ 10,000$ on trips and $22 \%$ spent NT $\$ 10,000$ to 20,000 . Only 22 subjects $(7.5 \%)$ stated that they visited alone; $34.9 \%$ were with friends, $26.4 \%$ with their spouses, $16.6 \%$ with organized group tours, and $11.5 \%$ with family or relatives. A majority $(69.8 \%)$ drove their own $(69.8 \%)$ or rented $(11.5 \%)$ vehicles to the coffee estates. Public transportation was used by $15.3 \%$.

\section{[Insert Table 3 about here]}

Regarding the attributes of visits to coffee estate, $52.5 \%$ visited coffee estates serving educational purposes; $24.7 \%$ to comprehensive venues; and $22.7 \%$ to traditional coffee estates. Day trips to coffee estates were made by $78 \%$, while the other $22 \%$ spent a night at or near the coffee estates. Those who stayed over used various accommodation types.

Considering the participation in experiential activities, some $68.5 \%$ said the visits deepened their knowledge on coffee planting; $64.1 \%$ had the chance to learn more about coffee processing methods; and $59.3 \%$ found how to tell the quality of coffee beans. Furthermore, learning about how to properly brew coffee was cited by $47.1 \%$; and $43.1 \%$ mentioned experiences making coffee by hand. Other experiences were trying coffee evaluation (39.7\%), experiencing coffee bean picking (39\%) and roasting (32.2\%), and learning about coffee roasting (29.5\%). 


\subsubsection{Confirmatory factor analysis, reliability, and validity}

Since MTES has been proven as a theoretical rigor model, the first step in the analysis was to validate the hypothesized model (Kline, 2014). CFA was performed to test if the sample of this study fit the proposed model. The results showed that value of Mardia's normalized estimation was 62.28, which is larger than the cutoff value 5.00 (Bentler, 2006). This indicated that the data had a positive kurtosis. According to Byrne (2013), the robust estimation should be performed in EQS in this situation. Therefore, Satorra-Bentler (S-B) scaled statistics instead of the maximum likelihood (ML) parameter were reported. The results of the CFA suggested that the data fit the proposed model properly $\left(\mathrm{S}-\mathrm{B} \chi^{2}{ }_{(245)}=\right.$ $354.663 ; p<0.01 ; \mathrm{SRMR}=0.051 ; \mathrm{CFI}=0.950 ; \mathrm{RMSEA}=0.048$ with $90 \%$ C.I. $=0.040$, 0.056). The higher-order factor, memorable tourism experience, accounted for all covariances among the seven first-order factors.

As Table 4 shows, factor loading of all measurement items ranged from 0.646 to 0.849 , exceeding the cutoff value of 0.45 (Tabachnick \& Fidell, 2007). Therefore, all measurement items fit the underlying latent constructs well. Two reliability coefficients indicated that the measurement scale had high internal consistency (Cronbach's alpha $=0.95$ and reliability coefficient rho $=0.96)$. Besides, the composite reliability $(\mathrm{CR})$ of the seven constructs tested was larger than 0.70 , also demonstrating satisfactory reliability. The average variance extracted (AVE) of all factors were greater than 0.50 , indicating that the validity of the hypothesized model was also supported (Fornell \& Larcker, 1981). A summary of the mean, standard deviation, factor loadings, CR and AVE of the model is shown in Table 4.

[Insert Table 4 about here]

The results disclosed that Taiwanese visitors were satisfied with the coffee tours and experiential activities offered by the coffee estates. Specifically, the visitors were satisfied with over $90 \%$ strongly agreeing or agreeing with every item in the MTES (Table 4). Only two items had average scores below four. Regarding the loadings of first-order factors on the second-order factors (MTEs), the highest regression coefficient was for meaningfulness (0.537), followed by novelty (0.508), involvement (0.508), and knowledge (0.467). This indicates that, for coffee estate visitors, meaningfulness explained more variance in MTEs than the other six factors. Thus, it was concluded that coffee estate visitors are more concerned about the meaning and importance of the tour, which is different from other types of leisure tourists who consume travel products mainly for hedonic purposes (e.g., Hirschman \& Holbrook, 1982; Miao, Lehto, \& Wei, 2011). If the coffee estate owners want to impress visitors, they should not focus on developing activities that just for fun. Instead, they should guide the visitors to see the meaning of the procedures of coffee production and inform the 
visitors about the significance of participation in the coffee tours to them.

Three other components with high loadings, novelty, involvement and knowledge, could be attributed to the activities such as the coffee farm tour, coffee bean picking, and roasting exclusively in coffee estates, even if most people have experience in brewing and tasting coffee by themselves. Together with the new knowledge about coffee plantations shared by owners, visitors more fully understand the growing of coffee from farm to table. In contrast to the informal and spontaneous pursuits of people in rural areas (Frochot, 2005), visitors to Taiwan's coffee estates in general actively participate in activities designed by owners and interact with locals to co-create tourism experiences, which fulfills their expectations for coffee tourism.

Jolliffe (2010) pointed out that many coffee farm owners view coffee tours or experiential activities as important opportunities to educate their customers about how various procedures make the differences that distinguish great coffees from each other. Meanwhile, scholars point out that learning new skills or gaining knowledge are the main motivations that drive tourists to visit leisure farms ( $\mathrm{Wu}, 2015)$. For example, Jou and $\mathrm{Wu}$ (2003) found that "continuous learning and development" is one of the five most significant motivations of leisure farm visitors, especially for single tourists. Since coffee estate tourists can be seen as one type of leisure farm visitor (Chang, 2003), the current study further compared if any dimension and the overall MTEs of educational coffee estate visitors are different from visitors to other types of estates. The results are presented in the following section.

\subsubsection{The differences of MTEs between educational and other coffee estate visitors}

To compare the differences in the seven dimensions of MTEs between educational coffee estate visitors and others, visitor data of educational coffee estates was extracted from others. Secondly, according to Byrne (2013), the mean of latent factors can be compared only if the model satisfy the following criteria: (1) configural invariance, (2) measurement (factor loading) invariance, and (3) intercepts of measured variables invariance. As Table 5 shows, all the CFI differences are less 0.01 (Cheung \& Rensvold, 2002); therefore, the equivalence of the model across the two visitor groups was validated. As a result, the subsequent testing for differences of means in the first-order (hedonism, novelty, social interaction and local culture, refreshment, meaningfulness, involvement, and knowledge) and second-order latent factor (MTEs) was proceeded. The visitors of non-educational coffee estates (traditional and comprehensive) were selected as the reference group and fixed to 0. As such, the factor means of the educational visitors were assessed to reflect the differences of MTEs between the two groups.

[Insert Table 5 about here] 
Table 6 shows the estimated value shows significant mean differences between educational and non-educational coffee estate visitors on both lower-order factors and the higher-order factor. Specifically, the results suggested that local culture and knowledge are two dimensions that educational visitors care about. Furthermore, the positive estimated value suggests that educational visitors have more memorable experiences than the visitors of other types of coffee estates. These results may be because educational coffee estates concentrate on providing professional knowledge of coffee and local culture to the public. For example, the educational coffee estate in this research, the Zo-chu Garden, integrates many aboriginal images of Zo-chu in its coffee bag design. The owner always reminds the visitors that the tribe is distinctive and nearly extinct, so people should cherish aboriginal people and their culture. In addition, he has won many championships in coffee bean contests and people are attracted to see and learn from him. It is perhaps not surprising that, knowledge and local culture are the most highly rated memorable experiences for educational coffee estates.

[Insert Table 6 about here]

\section{Managerial Implications for Rural Taiwan Coffee Estates}

The goal of this research was to analyze the tourism experiences offered by coffee estates in Taiwan, from both the supply and demand perspectives. Interestingly, although coffee tourism was judged to be in an embryonic stage, visitors were very satisfied with their coffee estate experiences along all dimensions.

\subsection{Experiences offered and challenges facing Taiwan coffee estates}

How to the coffee estates create visitor experiences? Most of the coffee estates in Taiwan are in rural areas where local culture and natural scenery are preserved. As a result, many coffee estates build visitor experiences and their brands based on the local culture and surroundings. The local culture is presented in new forms, so guests can learn more about it. This matches Mason's (2008) statement that by developing tourism, rural areas can preserve and revive traditional culture.

The Taiwan coffee estates still operate mainly on selling coffee beans with tourism experiences being a secondary consideration. Experiences are mainly offered so guests gain more coffee knowledge, making them more willing to buy the estates' coffee beans. Generally, there are no other specific tourism marketing activities. Most existing coffee 
estates have capacity limitations in space, personnel, skills and techniques. Each venue can only host a limited number of guests at a time, and it is difficult for coffee estates to promote at a larger scale. Having more guests than they can handle might result in negative impacts. This reflects Anbalagan and Lovelock's (2014) comment that coffee estates lack the ability to respond to large volumes of guests due to insufficient manpower.

Generally, coffee estates in Taiwan gain recognition from taking part in competitions as with other agricultural products. This approach is flawed since coffee contests normally only attract the attention of coffee enthusiasts, and broader exposure is not created. With such a limited portfolio of marketing activities, coffee tourism in Taiwan is highly vulnerable to market fluctuations. If coffee popularity declines or if domestic and international tourism weaken, this will seriously undermine the viability of small-scale coffee estates. Taiwan's coffee estates must significantly improve their marketing and branding practices - they currently do not have "the right brew." There are numerous opportunities to improve branding and expand marketing activities. Building multi-activity and multi-destination packages is one important option, especially in offering combined tickets or offers with nearby popular attractions. As Clancy (2008) proposes, professional travel agents and tour operators will expand the sales of these tours and packages to their client base. Collaboration among these coffee estates in joint marketing will be highly beneficial as well, perhaps following the product club model that is popular in Europe (e.g., the Wine Routes of Spain). Undoubtedly, the coffee estates must make much greater use of all forms of digital marketing and particularly social media.

\subsection{The niche market of Taiwanese coffee estate tourism}

What then, given the status and challenges, are the prospects for Taiwan's coffee tourism? The survey results reflect a high degree of satisfaction with visit experiences at the Taiwan coffee estates. The hedonism, knowledge, and involvement MTES' dimensions are highly rated. The results support Chandralal and Valenzuela's (2013) suggestions that tourist destination marketing should shift marketing strategies from highly focused on destination attributes to experiential aspects such as opportunities for social interactions and creating feelings of pleasure and arousal.

Taiwan is relatively convenient, safe, and secure when compared to other Asian, South American, and African countries where coffee originates. It takes less than three hours to reach most of the coffee estates from Taipei or two hours away from any major city on level paved roads, and the visit experiences can be carried with an absence of danger or physical injury. South American and African estate guests often must ride in jeeps over rugged mountain paths and be protected by armed security guards. This may represent a major competitive advantage for coffee estate tourism development in Taiwan. Additionally, the 
coffee market in Taiwan is undergoing steady growth and Taiwanese have more knowledge about coffee than before. Since many of the tours in Taiwan's coffee estates have educational purposes, the future has great potential and room for further development. New tourism in Asia will result from the expansion of niche markets in the future.

\subsection{Managerial and public-sector recommendations}

What needs to be done to further the potential of coffee tourism in Taiwan? This investigation recommends that the sustainable development of coffee estate tourism in Taiwan requires attention and significant improvement. The specific suggestions are: increasing and improving marketing and branding by government-run DMOs; developing an integrated tourism supply system and value chain in areas containing coffee estates; creating new coffee tour products with travel agencies and tour operators; and establishing education as the key selling point of coffee estates. These four initiatives will contribute to solving some of the challenges Taiwanese coffee estates are currently facing, while continuously developing the niche market of coffee estate tourism.

Increasing and improving DMO branding and marketing: All DMOs are departments of government in Taiwan. After the devastating earthquake on September 21, 1999, the Taiwanese government deployed the One Town One Product (OTOP) policy to encourage towns to come up with their own unique products, in turn enhancing the economic conditions of locals and communities. This policy gave new life to the Taiwanese coffee sector, which was virtually ignored for a long period of time. As the economy around coffee grew in Taiwan, coffee consumption expanded in Asia and worldwide; famous brands became household names. Coffee production and consumption as an enabler of tourism, recreation, and leisure accompanied this trend.

Taiwanese government agencies, whether in economic development, tourism or agriculture, should take inventory of the tourism resources and the special features and advantages of coffee estates in each region of the island. A tourism map geo-referencing and describing coffee estates should be created. A Taiwan coffee trail or circuit could be created, or product club or cluster of coffee estates established. These types of initiatives will help increase domestic and international visitors to Taiwan's coffee estates.

Developing an integrated tourism supply system and value chain in areas containing coffee estates: The supply system of tourism products mainly consists of tourist attractions, transportation systems, sightseeing service facilities, promotions, and tourist information (Gunn, 1994). However, most of Taiwan coffee estates are free-standing venues, unconnected to other attractions and players in the tourism system and value chain. Complete and integrated sightseeing systems should be established by strengthening the concept of a tourism community and making modifications such as adding food and accommodation so 
coffee estate guests extend the length of their stays, thus consuming more and enhancing local economies.

Creating new coffee tour products with travel agencies and tour operators:

Generally, the owners of Taiwanese coffee estates hold negative opinions on travel agencies. They perceive working with such agencies will lower their profits and may also result in poorer guest experiences. However, travel agencies in Taiwan and elsewhere have substantial client bases, along with well-established supplier relationships and distribution channels. They are professionals in the field of tourism who clearly recognize how to satisfy the needs of their clients; and this is what coffee estates generally lack. Jointly working with travel agencies to create new coffee estate package tours that are advertised through agencies' networks will increase business. This can provide a stable source of visitors to coffee estates, so they will have sufficient profits to increase manpower and create more career opportunities for local communities. Finally, Taiwanese coffee estates often have difficulty in communicating with foreign guests due to language and cultural differences. The professional capabilities of travel agencies can help eliminate such problems and expand the estates' international business.

Establishing education as the key selling point of coffee estates: The measurement of MTEs revealed that guests had high levels of satisfaction with the educational services provided by coffee estates. It might be assumed that coffee estate guests are motivated to acquire coffee-related knowledge. Thus, in the future, coffee estates can start from education and design activities or classes related to coffee know-how. This will raise guest satisfaction and market competitiveness.

\section{Limitations and Future Research Needs}

This research analyzed the tourism experiences in coffee estates in rural Taiwan. The owners of the venues were interviewed in depth, while their guests completed a mainly closed-ended survey questionnaire based on MTES. Theoretically, this research successfully replicated previous applications of MTES and indicated its flexibility of use in a variety of different tourism contexts.

More qualitative research with coffee estate guests and coffee lovers are still required to determine whether the coffee estate brands established by the Taiwan owners are recognized and fit consumer needs and expectations.

The coffee estates that currently can accommodate most guests are those of the educational type, and most completed questionnaires came from these estates. The fact that the survey could not be evenly distributed to all types of coffee estates for comparison and analysis is a limitation.

Another generator of the high levels of guest satisfaction in this survey was the interaction 
with local citizens. However, the nature and details of these interactions were not deeply analyzed in this research. Future studies should delve further into this factor and to suggest ways to link coffee estate tours with overall community development and tourism cluster creation.

This analysis reveals there is great scope for more research on coffee tourism worldwide. One of the major research questions to be addressed is why coffee as a highly popular beverage has not enjoyed the high levels of tourism development and marketing as have tea, wine and some other alcoholic beverages, and why coffee has not attracted more tourism research attention. In this respect, future researchers could start from the demand side and examine coffee estate marketing and product development from the guest perspective to define tourism service and product gaps and opportunities.

This research treated all visitors as being the same and there was no attempt made to segment the coffee estate visitor market. Future scholars should attempt to segment this market as there are known to many different groups of coffee drinkers and enthusiasts.

In addition, revisit intention should be measured and its relationship with experience satisfaction. Tours to coffee estates can deliver rich knowledge, but does greater understanding influence guests' inclination for or frequency of repeat visits? It will be useful to identify other innovative experience programming, apart from educational activities, that will make guests want to return to coffee estates.

Finally, as coffee estate tourism is not limited to Taiwan but is flourishing in other Asian countries such as Vietnam, Thailand, Indonesia, and Malaysia, comparisons among different countries' approaches would be valuable additions to the tourism and hospitality literature. 


\section{References}

Anbalagan, K., \& Lovelock, B. (2014). The potential for coffee tourism development in Rwanda - Neither black nor white. Tourism and Hospitality Research, 14(1-2), 81-96.

Bentler, P. M. (2006). EQS structural equations program manual. Encino, CA: Multivariate Software.

Byrne, B. M. (2013). Structural equation modeling with EQS: Basic concepts, applications, and programming (2nd ed.). Mahwah, NJ: Lawrence Erlbaum Associates, Inc., Publishers.

Byrne, B. M., \& Stewart, S. M. (2006). Teacher's corner: The MACS approach to testing for multigroup invariance of a second-order structure: A walk through the process. Structural Equation Modeling, 13(2), 287-321.

Chandralal, L., \& Valenzuela, F. R. (2013). Exploring memorable tourism experiences:

Antecedents and behavioural outcomes. Journal of Economics, Business and Management, 1(2), 177-181.

Chandralal, L., \& Valenzuela, F. R. (2015). Memorable tourism experiences: Scale development. Contemporary Management Research, 11(3), 291-310.

Chang, T.-C. (2003). Development of leisure farms in Taiwan, and perceptions of visitors thereto. Journal of Travel \& Tourism Marketing, 15(1), 19-40.

Cheung, G. W., \& Rensvold, R. B. (2002). Evaluating goodness-of-fit indexes for testing measurement invariance. Structural Equation Modeling, 9(2), 233-255.

Clancy, M. (2008). Cruisin' to exclusion: commodity chains, the cruise industry, and development in the Caribbean. Globalizations, 5(3), 405-418.

Clark, J. (2011). Coffee Journey: A tour to a remote coffee village in Thailand. Retrieved from https://www.nomadicnotes.com/visiting-a-coffee-farm-in-thailand/

Coffee De Amour(2015). Coffee estate tours in northern Thailand. Retrieved from https://hkccea.org/2015/09/24/chiang-mai-coffee-journey-2015/

Coffee De Amour(2016). Coffee estate tours in northern Thailand. Retrieved from https://hkccea.org/2016/08/01/2016-thailand-origin-trip/

Coffee De Amour(2017). Coffee estate tours in northern Thailand. Retrieved from https://hkccea.org/2017/01/21/chiangrai-majentai-coffee/

Cohen, E. (1979). A phenomenology of tourist experiences. Sociology, 13(2), 179-201.

Creswell, J. W. (2012). Qualitative inquiry and research design: Choosing among five approaches (3rd ed.). London, UK: Sage.

Creswell, J. W., \& Clark, V. L. P. (2011). Designing and Conducting Mixed Methods Research. Thousand Oaks, CA: SAGE. 
Curran, P. J., West, S. G., \& Finch, J. F. (1996). The robustness of test statistics to nonnormality and specification error in confirmatory factor analysis. Psychological Methods, 1(1), 16-29.

Devesa, M., Laguna, M., \& Palacios, A. (2010). The role of motivation in visitor satisfaction: Empirical evidence in rural tourism. Tourism Management, 31(4), 547-552.

Enders, C. K. (2001). A primer on maximum likelihood algorithms available for use with missing data. Structural equation modeling, 8(1), 128-141.

Fornell, C., \& Larcker, D. F. (1981). Evaluating structural equation models with unobservable variables and measurement error. Journal of Marketing Research, 18, 39-50.

Frochot, I. (2005). A benefit segmentation of tourists in rural areas: A Scottish perspective. Tourism Management, 26(3), 335-346.

Gathura, M. N. (2013). Factors affecting small-scale coffee production in Githunguri District, Kenya. International Journal of Academic Research in Business and Social Sciences, 3(9), 2222-6990.

Ghapar, A. A., Jamal, S. A., \& Ahmad, K. N. (2015). Sustainable tourism development: A study on community resilience for rural tourism in Malaysia. Procedia-Social and Behavioral Sciences, 168, 116-122.

Graham, J. W. (2009). Missing data analysis: Making it work in the real world. Annual Review of Psychology, 60, 549-576.

Gursoy, D., Chi, C. G. \& Dyer, P. (2010). Locals' attitudes toward mass and alternative tourism: The case of Sunshine Coast, Australia. Journal of Travel Research, 49(3), 38194

Hirschman, E. C., \& Holbrook, M. B. (1982). Hedonic consumption: Emerging concepts, methods and propositions. Journal of Marketing, 46(3), 92-101.

Huang, J. L. (2017). How to Develop a Coffee Tourism Destination? The Case of Gukeng, Taiwan. Master dissertation of Chi Nan University.

Irshad, H. (2010). Rural tourism - An overview. Edmonton, Canada: Government of Alberta, Agriculture and Rural Development.

Jolliffe, L., Kwan, K., \& Yen, G. K. (2010). Coffee in Vietnam: International Tourist Experiences. In L. Jolliffe (Ed.), Coffee Culture, Destinations and Tourism (pp. 89-98). Clevedon, UK: Channel View Publishing.

Jolliffe, L. (2010). Coffee culture, destinations and tourism. Clevedon, UK: Channel View Publishing.

Jou, J., \& Wu, C. (2003). A research on leisure farm tourists' motivation, information search behavior, and evaluation criteria in Taiwan. Journal of Tourism Studies, 9(2), 23. 
Karlsson, H., \& Karlsson, J. (2009). Coffee Tourism: A community development tool. Retrieved March 28, 2018, from

http://www.diva-portal.org/smash/get/diva2:220789/FULLTEXT02

Karlsson, P., \& Karlsson, B. (2017). The four successful types of wine tourism. Retrieved March 28, 2018, from

https://www.forbes.com/sites/karlsson/2017/07/21/the-four-successful-types-of-wine-to urism/\#60fc803036fa

Kastenholz, E., Carneiro, M. J., Marques, C. P., \& Lima, J. (2012). Understanding and managing the rural tourism experience. Tourism Management Perspectives, 4, 207-214.

Kim, J. H. (2018). The impact of memorable tourism experiences on loyalty behaviors: The mediating effects of destination image and satisfaction. Journal of Travel Research, 57(7), 856-870.

Kim, J. H., Ritchie, J. R. B. \& McCormick, B. (2012). Development of a scale to measure memorable tourism experiences. Journal of Travel Research, 51(1),12-25.

Kim, J. H., \& Ritchie, J. R. B. (2014). Cross-cultural validation of a memorable tourism experience scale (MTES). Journal of Travel Research, 53(3), 323-335.

Kleidas, M. \& Jolliffe, L. (2010). Coffee attraction experiences: A narrative study. Tourism Preliminary Communication, 58(1), 61-73.

Kline, R. B. (2014). Principles and practice of structural equation modeling (3rd ed.). New York, NY: Guilford Publications.

Krishna, A. (2011). An integrative review of sensory marketing: Engaging the senses to affect perception, judgment and behavior. Journal of Consumer Psychology, 22(3), 332-351.

Lyon, S. (2013). Coffee tourism and community development in Guatemala. Human Organization, 72(3), 188-198.

MacCallum, R. C., Browne, M. W., \& Sugawara, H. M. (1996). Power analysis and determination of sample size for covariance structure modeling. Psychological methods, 1(2), 130-149.

Mannell, R. C., \& Iso-Ahola, S. E. (1987). Psychological nature of leisure and tourism experience. Annals of tourism research, 14(3), 314-331.

Mason, P. (2008). Tourism impacts, planning and management. Oxford, UK:

Butterworth-Heinemann.

Miao, L., Lehto, X., \& Wei, W. (2011). The hedonic experience of travel-related consumption. In International CHRIE conference-referred track. Paper 7 http://scholarworks.umass.edu/refereed/ICHRIE_2011/Saturday/7.

Nursey-Bray, M., \& Rist, P. (2009). Co-management and protected area management: achieving effective management of a contested site, lessons from the Great Barrier Reef World Heritage Area (GBRWHA). Marine Policy, 33(1), 118-127. 
Otto, J. E., \& Ritchie, J. B. (1996). The service experience in tourism. Tourism Management, $17(3), 165-174$.

Pine, B. J., \& Gilmore, J. H. (2011). The experience economy. Boston, MA: Harvard Business Press.

Rekom, J. V., and F. Go. (2006). Being discovered: A blessing to local identities? Annals of Tourism Research, 33(3), 767-84.

Rogerson, C. M., \& Rogerson, J. M. (2014). Agritourism and local economic development in South Africa. Bulletin of Geography. Socio-economic Series, 26(26), 93-106.

Scherl, L. M., \& Edwards, S. (2007). Tourism, indigenous and local communities and protected areas in developing nations. In R. Bushell \& P. F. J. Eagles (Ed.), Tourism and protected areas: Benefits beyond boundaries (pp. 71-88). Cambridge, MA: CABI.

Sick, D. (2008). Coffee, farming families, and fair trade in Costa Rica: New markets, same old problems? Latin American Research Review, 43(3), 193-208.

Stylianou-Lambert, T. (2011). Gazing from home: Cultural tourism and art museums. Annals of Tourism Research, 38(2), 403-421.

Swarbrooke, J. (1995). The development and management of visitor attractions. Oxford, UK: Butterworth Heinemann.

Tabachnick, B. G., \& Fidell, L. S. (2007). Using multivariate statistics (5th ed.). Boston, MC: Pearson Education.

Trukhachev, A. (2015). Methodology for evaluating the rural tourism potentials: A tool to ensure sustainable development of rural settlements. Sustainability, 7, 3052-3070.

Tung, V. W. S., \& Ritchie, J. B. (2011). Exploring the essence of memorable tourism experiences. Annals of Tourism Research, 38(4), 1367-1386.

Utting-Chamorro, K. (2005). Does fair trade make a difference? The case of small coffee producers in Nicaragua. Development in Practice, 15(3-4), 584-599.

Williams, P., \& Soutar, G. N. (2009). Value, satisfaction and behavioural intentions in an adventure tourism context. Annals of Tourism Research, 36(3), 413-38.

$\mathrm{Wu}, \mathrm{C} . \mathrm{-W}$. (2015). Foreign tourists' intentions in visiting leisure farms. Journal of Business Research, 68(4), 757-762.

Yun, O. (2014). Coffee tourism in Ethiopia: Opportunities, challenges, and initiatives. (Unpublished doctoral dissertation). University of Exeter, Exeter, United Kingdom. Retrieved March 28, 2018, from https://ore.exeter.ac.uk/repository/handle/10871/17470

\section{Acknowledgement}

This research was partially supported by Higher Education Sprout Project funded by the Ministry of Education, Taiwan under Grant No. 107A42. 